ORIGINAL ARTICLE

AFRICAN JOURNAL OF CLINICAL AND EXPERIMENTAL MICROBIOLOGY AJCEM/201179/21203

COPYRIGHT 2012

AFR. J. CLN. EXPER. MICROBIOL 13(2): 90-93 http://dx.doi.org/10.4314/ajcem.v13i2.6
MAY 2012 ISBN 1595-689X VOL 13(2) -http://www.ajol.info/journals/ajcem

\title{
EVALUATING THE EFFICACY OF TOPICAL SILVER NITRATE AND INTRAMUSCULAR ANTIMONIAL DRUGS IN THE TREATMENT OF CUTANEOUS LEISHMANIASIS IN SOKOTO, NIGERIA
}

\author{
${ }^{1}$ Igbineweka O.O., ${ }^{2}$ Aghedo F.I., ${ }^{3}$ Idusuyi O. , ${ }^{4}$ Hussain N.A. \\ 1 Brigade Medical Centre, Gingiya Military Barracks, Sokoto ${ }^{1}$, Department of Hematology and Blood Transfusion \\ Science, Usmanu Danfodiyu University Teaching Hospital, Sokoto², Department of Pharmacology, Usmanu \\ Danfodiyu University, Sokoto ${ }^{3}$ Department of Preventive Health, Military Hospital, Lagos ${ }^{4}$
}

Correspondence e-mail: naahussain@yahoo.co.uk

\begin{abstract}
Background: Cutaneous leishmaniasis (CL) is a disease of public health importance in Nigeria, with high prevalence in the Northwest and Northeastern part of the country. The side effects of antimonial drugs \{stibogluconate (SSG) and meglumine antimoniate\} in the treatment of CL have often resulted in poor drug adherence and default by patients and possible drug resistance. The increasing default to follow-up and the significant side effects associated with antimonial therapy necessitated the dire need of alternative therapeutic modalities. Thus, this study aimed at comparing the efficacy of topical silver nitrate with the antimonial drugs in the treatment of CL.

Methods: A total of 95 patients with clinically diagnosed leishmaniasis and parasitologically proven CL participated in the study after their informed-consent had been obtained. The treatment selection was optional to the participants. Sixty (63.2\%) patients received alternative therapy of topical silver nitrate as a single dose while $35(36.8 \%)$ patients received antimonial therapy for 21 days at $20 \mathrm{mg} / \mathrm{kg}$ body weight.

Results: On day 30 of treatment, $68(86.1 \%)$ lesions among patients on topical silver nitrate healed completely as compared with only $5(6.8 \%)$ among those on i.m. SSG. There was no improvement in $25(34.2 \%)$ lesions among those on i.m. SSG compared with only $1(1.2 \%)$ lesion among those on topical silver nitrate. Overall, there was a statistically significant difference in the cure rate among patients on silver nitrate as compared with those on i.m. SSG on the $21^{\text {st }}$ and $30^{\text {th }}$ days of treatment. $(\mathrm{p}<0.05)$.

Conclusion: Topical silver nitrate therapy is an effective and better drug treatment for CL among this study population.
\end{abstract}

Keywords: Cutaneous leishmaniasis, efficacy, Silver nitrate, Sodium Stibogluconate, Sokoto

\section{INTRODUCTION}

Leishmaniasis is an infection that is caused by an obligate intracellular protozoa of the genus Leishmania; first described in 1903 by Leishman and Donovan. The natural transmission of
Leishmania parasites is carried out by sandflies of the genus Phlebotomus or Lutzomyia (1). These parasites cause three forms of leishmaniasis according to the localization of the parasites in mammalian tissues, notably visceral, cutaneous, and mucosal leishmaniasis. The outcome of infection depends on the species of Leishmania 
parasites and the host's immune response (2). Visceral leishmaniasis (VL) is the most severe form of leishmaniasis involving internal organs such as the spleen and liver and is fatal if left untreated (3).

Globally, about 350 million people live in areas of active transmission of Leishmania, with estimated 14 million people directly affected in Africa, Asia, Europe, and America (4). The global burden of leishmaniasis has remained stable for some years, causing a morbidity and mortality loss of 2.4 million Disability Adjusted Life-Years (DALYs) and approximately 70,000 deaths; a significantly high figure ranked among communicable diseases $(5,6)$. Leishmaniasis and Human Immunodeficiency Virus (HIV) co-infection has surged as a major complication of leishmaniasis and has ignited calls for the recognition of leishmaniasis as an Acquired Immunodeficiency Syndrome (AIDS) defining-illness (7). In Africa, particularly Ethiopia and Sudan, it is estimated that $70 \%$ of adults with VL also have HIV infection (8).

Northern Nigeria is one of the West African endemic CL foci, especially in Sokoto, Gusau, Katsina, Maiduguri and Azare9 . Between 1924 and 1941, the Nigeria health services recorded 131 cases of CL and 5 cases of VL, but there was no indication that these cases were parasitologically confirmed. In 1942, smears of 14 patients from Kano with cutaneous sores were confirmed parasitologically to be leishmaniasis. However, the first case of CL in Nigeria was officially reported in $1944(9,10)$. In spite of the initial public health efforts on CL in this region, there is dearth of follow-up data on CL caused by
Leishmania tropica and its treatment-induced cure rates.

The current management of leishmaniasis are drug treatment of patients, to alleviate disease and vector control to reduce its transmission. Pentavalent antimonials (namely, sodium stibogluconate (SSG) and meglumine antimoniate) are the mainstay of anti-leishmanial therapy (11-13). However, the antimonials have serious adverse effects (such as pancreatitis, hepatotoxicity, and cardiotoxicity) when given intramuscularly $(14,16)$ and are expensive (17). Moreover, the lengthy course of its administration and associated pain often results in low drug adherence, default and ultimately, drug resistance $(18,18)$. Bearing in mind several studies that have shown the high efficacy of colloidal silver as an antimicrobial $(20,-23)$, the topical silver nitrate appears to be the most feasible alternative. Silver is toxic to microorganisms by poisoning respiratory enzymes and components of the microbial electron transport system as well as impairing some DNA function ${ }^{24,25}$. Additionally, silver has been shown to interact with structural proteins and preferentially bind with DNA bases to inhibit replication $(26,27)$.

Therefore, in order to achieve effective control of $\mathrm{CL}$, it is pertinent to try other drug-treatment modalities which are painless, tolerable, and of short duration. Hence the focus of this study which compared the efficacy of the topical silver nitrate therapy with the antimonials in the treatment of CL due to L. tropica in Sokoto, Northwest Nigeria. 


\section{MATERIALS AND METHODS}

Study location and Participants. The study was carried out at 1 Brigade Medical Centre which is located in Gingiya military barracks, Sokoto, Northwest Nigeria. Established in 1984, the medical centre is well staffed, with equipped laboratory and provides curative and preventive services to the soldiers, their families and the civil populace. It is also a designated centre by the Sokoto State Ministry of Health and the Nigerian Ministry of Defence-US Department of Defense (NMOD-USDoD) for the treatment of Leishmaniasis and HIV/AID respectively.

Ninety five patients, aged more than 5 years with parasitologically confirmed CL lesions were recruited for the study. The exclusion criteria were pregnancy, breast-feeding mothers, patients who had a major surgery in the previous 3 months, presence of any uncontrolled medical condition; anticipated unavailability for followup; and patients allergic to antimonials and silver nitrate.

Ethical issues: The authority of the Medical Centre and State's ethics committee approved the study protocol and the consent form. New and eligible patients attending the clinic for treatment were briefed about the aim and protocol of the study. Patients were enrolled in the study after an informed consent had been given. All medical services provided during the study were free.

Participant's Medical History: Prior to the study, a detailed medical and personal history of each participant was taken. These included the duration of symptoms, residence in or travel through a possibly leishmaniasis-endemic area, history of any existing health condition, menstrual and parity history, previous treatments and outcome. A general physical examination was also carried out to assess the location, size of lesions with other characteristics such as infiltration, erythema, scaling and ulceration.

Parasitological confirmation: Parasitological confirmation of $\mathrm{CL}$ was by microscopic examination of smear and with RIDASCREEN leishmania antibody test kit (R-Biopharm, Germany). Scrapings from the lesion edge were smeared onto a slide, and the slide was dried, fixed with methanol, stained with Giemsa and examined under the microscope at $x 100$ magnification for presence of Leishmania amastigotes. For each, patient, 2 slides were prepared and all positive slides were rechecked and confirmed by at least 2 laboratory scientists. For leishmania antibody testing about $3 \mathrm{mls}$ of whole blood was collected from each participant into a clean dry plain blood container and allowed to clot. The blood sample was spun with a bench centrifuge at 5000rpm for 5 minutes and the serum separated into another clean plain container and stored frozen prior to testing at $20^{\circ} \mathrm{C}$. The samples were tested using Elisa leishmania antibody kit (R-Biopharm, Germany), using the procedure as described in the manual of the kit.

\section{Treatment Procedure}

Sixty patients had a single dose topical silver nitrate treatment while 35 had daily intramuscular administration of SSG for 21 days using the World Health Organization recommended treatment for CL (28). For intramuscular administration, $20 \mathrm{mg} / \mathrm{kg}$ of SSG was administered daily (up to a maximum daily dose of $850 \mathrm{mg}$ ) for 21 days (28). For silver nitrate 
treatment, the surface of the each lesion was cleaned with hydrogen peroxide solution and scraped with scalpel blade. The lesion surface was mopped with cotton wool to prevent bleeding; fine granules of silver nitrate were poured into it, covered with water-soaked cotton wool and dressed with plaster for 24 hours. After 24 hours, each lesion was cleaned daily with hydrogen peroxide and covered with Gentamycin-ointment smeared bandage for 21 days. Also, in order to prevent secondary infection, each patient on the topical silver nitrate had $280 \mathrm{mg}$ of intramuscular Gentamycin for 5 days. Treatment efficacy was measured by the percentage of patients cured on $21^{\text {st }}$ and $30^{\text {th }}$ day after commencing treatment. "Cure" is defined as "the complete re-epithelialization of the CL lesion, with no evidence of papules, inflammation, or indurations".
Data collation and analysis.. The obtained data were analyzed using EPI info computer software package. The results were displayed in tables and Chi square test statistic was used at $95 \%$ level of significance.

\section{RESULTS}

A total of 95 patients comprising 74 males (77.9\%) and 21 females (22.1\%) were recruited for the study as shown in Table 1. Thirty five patients (with a total of 73 lesions) received i.m. SSG while 60 (with a total of 79 lesions) received topical silver nitrate treatment. In both groups, each male patient had an average of 1-2 lesions while each female had an average of 2-5 lesions; thus implying that the lesions were more among females than males. The age range of the patients who had intramuscular SSG was 31-42 years (mean $=30.5)$ while that of patients who had topical silver nitrate was 16-52 years (mean = 32.4).

\section{TABLE 1: CHARACTERISTICS OF PATIENTS WITH CUTANEOUS LEISHMANIASIS TREATED WITH INTRAMUSCULAR SSG AND TOPICAL SILVER NITRATE}

\begin{tabular}{|c|c|c|c|}
\hline \multirow{2}{*}{ Characteristics } & Intramuscular SSG (\%) & Topical Silver Nitrate (\%) & \multirow[t]{2}{*}{ Total $(\mathbf{1 0 0 \% )}$} \\
\hline & Female & Female & \\
\hline No of Patients & $30(31.6 \%) \quad 5(5.3)$ & $44(46.3)$ & 95 \\
\hline No of Lesions & $44(28.9)$ & $41(27 \%)$ & 152 \\
\hline $\begin{array}{l}\text { Mean Age and Range } \\
\text { (in years) }\end{array}$ & $30.5(13-42)$ & $32.4(16-52)$ & \\
\hline
\end{tabular}

Table 2 showed that the nodular/nodularulcerative lesions were the commonest (constituting $82.1 \%$ and $73.4 \%$ in i.m. SSG and topical silver nitrate groups respectively). Over two-third lesions were located in the upper limbs in each treatment category (i.m. SSG $=65.8 \%$, topical silver nitrate $=68.3 \%)$. No lesion was seen in the groin, perineum or buttocks in both treatment categories.

Table 3 showed the cure rate in each category after $21^{\text {st }}$ and $30^{\text {th }}$ day of treatment. On day 21 , Sixty five $(82.3 \%)$ lesions among patients on topical silver nitrate healed completely compared 
with $4(5.5 \%)$ among those on i.m. SSG. There was no improvement in $30(41 \%)$ lesions of patients on i.m. SSG compared with 4 (5.1) among those on topical silver nitrate. On day 30 of treatment, 68 (86.1\%) lesions among patients on topical silver nitrate healed completely as compared with only 5 (6.8\%) among those on i.m. SSG. Also, there was no improvement in 25 (34.2\%) lesions among those on i.m. SSG compared with only 1 (1.2\%) lesion among those on topical silver nitrate. There was a statistically significant difference in the cure rate among patients on silver nitrate as compared with those on i.m. SSG on the $21^{\text {st }}$ and $30^{\text {th }}$ days of treatment. $(\mathrm{p}<0.05)$.

Apart from complaints of pain at the site of injections, which was generally greater in the patients who were given i.m SSG, the medications were well-tolerated. For each patient, the results of the post-treatment biochemical and hematological investigations were normal.

TABLE 2: CHARACTERISTICS OF THE CUTANEOUS LEISHMANIASIS LESIONS OF THE 95 PATIENTS TREATED

\begin{tabular}{|l|cc|}
\hline \multicolumn{1}{|c|}{ Characteristics of Lesions } & $\begin{array}{c}\text { Type of Treatment } \\
\text { Intramuscular SSG } \\
(\mathrm{n}=73 \text { lesions) }\end{array}$ & $\begin{array}{c}\text { Topical Silver nitrate } \\
(\mathrm{n}=79 \text { lesions) }\end{array}$ \\
\hline & & \\
Mean area of lesion and & & $1.7(0.5-4.0)$ \\
range (in cm $\left.{ }^{2}\right)$ & $1.8(0.6-4.6)$ & \\
Lesion type (\% of lesions) & & \\
& & \\
Nodular & & \\
Nodular-ulcerative & & $37(46.8)$ \\
Flat-ulcerative & $32(43.8)$ & $21(26.6)$ \\
Plaque-like & $28(38.3)$ & $13(16.4)$ \\
Lesion site (\% of lesion) & $10(13.7)$ & $8(10.1)$ \\
Shoulder & $3(4.1)$ & \\
Upper arm & & \\
Elbow & & $5(6.3)$ \\
Lower arm & $8(10.9)$ & $14(17.7)$ \\
Hand & $10(13.7)$ & $4(5.1)$ \\
Thigh & $3(4.1)$ & $20(25.3)$ \\
Knee & $18(24.7)$ & $11(13.9)$ \\
Leg & $9(12.3)$ & $2(2.5)$ \\
Foot & $4(5.5)$ & $5(6.3)$ \\
& $2(2.7)$ & $15(19)$ \\
& $13(17.8)$ & $3(3.8)$ \\
\hline
\end{tabular}

\section{DISCUSSION}

There have been several attempts in the past to develop a safe and simply administered drug with a broad spectrum of activity against CL. For example, high cost and painful injections are documented drawbacks of treatment by antimonial compounds(14,15). In addition, the antimonial drugs have been documented to have $80-85 \%$ cure rate, recurrent clinical signs and relapses (16). Thus, the dire need to develop effective compounds for the treatment of CL that would be economical, ease of administration and 
could avoid resistance becomes expedient. To surmount this challenge, topical/local treatment of CL lesions seems a logical alternative. Although some forms of topical/local therapy have been in long use in endemic areas by traditional practitioners, they had little if any effect (27).

In this study, more than three-quarter of the selected patients were males. The few female participants could be attributed to the exclusion criteria which included pregnant women and breastfeeding mothers. The patients were given the option of choosing a treatment regimen after the informed consent had been obtained and this accounted for the selection of silver nitrate treatment by $60(63.2 \%)$ of the 95 patients. For each treatment regimen, it was observed that the male patients had an average of 1-2 lesions while females had an average of 2-5 lesions; thus implying that the lesions were more among females than males. The reason(s) for this variation cannot be explained since both gender were equally exposed to the vector. Further research to determine this variation is desirable. Also, in both treatment regimen, it was observed that over two-third lesions were located in the upper limbs (i.m. SSG $=65.8 \%$, topical silver nitrate $=68.3 \%$ ) and none was seen in the groin, perineum or buttocks. This finding implies that the exposed parts of the body were more accessible to the vector. It is therefore necessary to emphasize the use of protective clothes by the communities; especially while in the farm (or grazing animals); as an important preventive measure against the vector bites.

TABLE 3: COMPARISON OF THE CURE RATE AMONG PATIENTS ON INTRAMUSCULAR SSG AND TOPICAL SILVER NITRATE

\begin{tabular}{|c|c|c|c|c|}
\hline $\begin{array}{c}\text { Duration (in } \\
\text { days) }\end{array}$ & Cure Rate & $\begin{array}{c}\text { IM SSG (\%) } \\
(n=73)\end{array}$ & $\begin{array}{l}\text { Topical Silver Nitrate }(\%) \\
(\mathrm{n}=79)\end{array}$ & P value \\
\hline $\begin{array}{l}\text { Day } 21 \text { of } \\
\text { treatment }\end{array}$ & $\begin{array}{l}\text { Fully healed lesions } \\
\text { Improved lesions } \\
\text { No change in lesion } \\
\text { Worsened lesion }\end{array}$ & $\begin{array}{c}4(5.5) \\
39(53.4) \\
25(34.2) \\
5(6.8) \\
\end{array}$ & $\begin{array}{c}65(82.3) \\
10(12.7) \\
4(5.1) \\
- \\
\end{array}$ & 0.00000 \\
\hline $\begin{array}{l}\text { Day } 30 \text { of } \\
\text { treatment }\end{array}$ & $\begin{array}{l}\text { Fully healed lesions } \\
\text { Improved lesions } \\
\text { No change in lesion } \\
\text { Worsened lesion }\end{array}$ & $\begin{array}{c}5(6.8) \\
43(58.9) \\
21(28.8) \\
4(5.4)\end{array}$ & $\begin{array}{c}68(86.1) \\
10(12.7) \\
1(1.2) \\
-\end{array}$ & 0.00000 \\
\hline
\end{tabular}

More than four-fifth $(82.3 \%)$ of the lesions among patients on topical silver nitrate and only $5.5 \%$ lesions those on i.m. SSG healed completely on the $21^{\text {st }}$ day of commencing treatment. By the 
30th day, $86.1 \%$ of the lesions among those on silver nitrate had healed completely as compared with only $6.8 \%$ among those on i.m. SSG. There was a statistically significant difference in the cure rate between patients on silver nitrate and those on i.m. SSG on the $21^{\text {st }}$ and $30^{\text {th }}$ days of treatment. $(p<0.05)$.

Conclusion: In comparing the efficacy of topical silver nitrate and i.m. SSG in the treatment of CL, this study has shown that a single dose treatment with topical silver nitrate plus topical gentamycin (for secondary infections) was more effective. The

\section{REFERENCES}

1. Mandell GL, Bennett JE, Dolin. In Mandell, Douglas, and Bennett's Principles and practice of infectious diseases. Elsevier, $6^{\text {th }}$ edn. 2005: 24282442.

2. Roberts MTM. Current understandings on the immunology of leishmaniasis and recent developments in prevention and treatment. Br. Med.Bull: 2006; 76: 115-130.

3. Mauel J.. Vaccination Against Leishmania Infections. Current drug targets. immune. Endocr. Metabol. Disord.2002; 2: 201- 226.

4. World Health Organization. Control of Leishmaniasis. 2006 Report of the secretariat. www.who.int/gb/ebwha/pdf_files/EB118/B118 4-en.pdf

5. Davies CR, Kaye P, Croft SL, Sundar S. Leishmaniasis: New approaches to disease control. BMJ. 2003; 326: 377- 382.

6. Reithinger R, Dujardin JC, Louzir H, Pirmez C, Alexander B. and Brooker S. Cutaneous Leishmaniasis. Lancet. Infect. Dis. 2007: 581- 596

7. Singh S. New developments in diagnosis of leishmaniasis. Indian. J. Med. Res.2006;123: 311330 . study also highlighted the need to educate the community on the use of protective clothing to reduce the bite by the vector. The reasons for the gender variation in the number of CL lesions among this study needs to be further researched.

\section{ACKNOWLEDGMENT}

We are grateful to the management and staff of 1 Brigade Medical Centre, Gingiya Barracks for their facility and cooperation during the period of the study.

8. Desjeux P. The increase in risk factors for leishmaniasis worldwide. Trans. R. Soc. Trop. Med. Hyg. 2001; 95: 239- 243.

9. Jelliffe RS. Cutaneous Leishmaniasis in Nigeria and the western Sudan. West Afr. Med J. 1995;4:92-94.

10. Handmann E. Leishmaniasis: Current status of vaccine development. Clin Microbiol Rev. 2001;14:229-243.

11. Berman JD. Human Leishmaniasis: clinical, diagnostic and chemotherapeutic developments in the last ten years. Clin Infect Diseases.1997; 24:684-703.

12. Croft SL, Yardley V. Chemotherapy of Leishmaniasis. Curr Pharm Design. 2002; 8:273301.

13. Croft SL, Coombs GH. LeishmaniasisCurrent chemotherapy and recent advances in the search for novel drugs. Trends Parasitol; 2003; 19: 502-8.

14. Boelaert M, LeRay D, Van Der Stuyft P. How better drugs could change kala-azar control: lessons from a cost-effectiveness analysis. Trop Med Int Health.2002;7:955-959.

15. Aronon NE, Wortman GW, Jackson JE, Gasser RA Jr, Magill JA et al. Safety and efficacy of intravenous sodium stibogluconate in the treatment of leishmaniasis: recent US military experience. Clin Infect Dis.1998; 27: 1457-1464. 
16. Bryceson A. A policy for leishmaniasis with respect to the prevention and control of drug resistance. Trop Med Int Health.2001;6:928-934.

17. Dowlati Y. Cutaneous leishmaniasis: clinical aspect. Clin Dermatol; 1996;14: 425-431.

18. Romero GAS, Guerra MVS, Paes MG, Macedo VO. Comparison of Cutaneous leishmaniasis due to leishmania braziliensis and leismania guyanensis in Brazil: Therapeutic response to meglumine antimonite. Am J Med Hyg.2001; 65:456-465.

19. Rojas R, Valderrama L, Valderamma M, Varona MX, Quettette $\mathrm{M}$ et al. Resistance to antimony and treatment failure in human leishmaniasis infection. J Infect Dis. 2006;193:13751383.

20. Lockman Y, Vardy D, Ohayon D, Elon J. The failure of traditionally used desert plants to act against cutaneous leishmaniasis in experimental animals. Annals of Tropical Medicine and Parasitology .1991; 85: 499-501.

21. Gunawan C, Teoh WY, Marquis CP, Lifla J, Amal R. Reversible antimicrobial photoswittching in nanosilver. Small.2009;5 (3):341-344.

22. Mehrbod P, Motamed N, Tabatabaian M, Soleimani Estyar R, Amini E, Shahidi M, Tavasoti- Kheiri M. In Vitro Antiviral Effect of "Nanosilver" on Influenza Virus. DARU. 2009;17: 88-93.

23. Trop M, Novak M, Rodl S, Hellbom B, Kroell W, Goessler W. Silver-coated dressing acticoat caused raised liver enzymes and argyria-like symptoms in burn patient. Journal of Trauma. 2006; 60 (3): 648-652.

24. Mooney EK. Silver dressings [safety and efficacy reports]. Plast Reconstr Surg; 2006; 117(2): 666-669.

25. Poon VK, Burd A. In vitro cytotoxity of silver: implication for clinical wound care. Burns; 2004; 30:140-147.

26. Dunn K, Edwards-Jones V.. The role of Acticoat TM with nanocrystalline silver in the management of burns. Burns; 2004;30: 81-91.

27. Reyburn, HA. Guide to the treatment of cutaneous leishmaniasis. Kabul, Afghanistan: World Health Organization. 2000. 